\title{
HISTÓRIA DA PAISAGEM E PAISAGENS SEM HISTÓRIA; A PRESENÇA HUMANA NA FLORESTA ATLÂNTICA DO SUDESTE BRASILEIRO
}

\author{
Rogerio Ribeiro de Oliveira* \\ Carlos Engemann***
}

Resumo: O estudo da transformação da paisagem tem colocado o foco nas atividades humanas nos ecossistemas nas chamadas populações tradicionais e a respectiva influência nos padrões ecológicos e biogeográficos contemporâneos. No caso da Floresta Atlântica, cuja ocupação humana data de milhares de anos, existe um longo histórico de transformação de suas condições ambientais por essas populações, cuja história é pouco conhecida. A grande maioria das informações que se dispõe sobre estas populações encontra-se inseridas no próprio ecossistema, o que pode ser obtido tanto por vestígios arqueológicos, Como pelo estudo da estrutura e composição da floresta. Assim, a Mata Atlântica, tal como a conhecemos hoje, pode ser interpretada como um documento histórico que potencialmente evidencia e descreve a resultante da interação de seres humanos com o ecossistema.

Palavras-chave: Populações tradicionais. Transformação da paisagem. História Ambiental. Ecossistema.

\begin{abstract}
The study of landscape transformation has focused the human activities on ecosystems performed by the so called traditional populations and its influence on contemporary ecologic and biogeographyc patterns. There is a long history of transformation of their environmental conditions done by these populations, whose history is little known. Most of the information that is available about these populations is included in the ecosystem, which can be obtained by both archaeological and the study of structure and composition of the forest. Thus, the Atlantic Forest, as is known today may be interpreted as a historical document that describes and shows the result of the interaction of humans with the ecosystem in many of its attributes.
\end{abstract}

Keywords: Traditional population. Landscape transformation. Environmental History. Ecosystem.

\footnotetext{
* Professor e pesquisador na Pontifícia Universidade Católica do Rio de Janeiro - PUC RIO. E-mail: rro@puc-rio.br

** Professor e pesquisador na Universidade Salgado de Oliveira - UNIVERSO.

E-mail: carlos.engemann@gmail.com
} 
História da paisagem e paisagens sem história: a presença humana na Floresta Atlântica do Sudeste Brasileiro

\section{INTRODUÇÃO}

O reconhecimento da importância da História Ambiental e os seus legados ambientais têm colocado o foco em atividades humanas como um legítimo e essencial assunto nas ciências ambientais. Assim, cabe à História Ambiental, campo de convergência de saberes ligados ao meio ambiente, a difícil tarefa de interpretar a paisagem do presente à luz das escolhas e ações feitas pelas populações no passado. Roderick Nash, um dos primeiros autores a utilizar o termo História Ambiental no final da década de 1960, sugeriu que a paisagem fosse interpretada como um documento histórico. ${ }^{1} \mathrm{O}$ estudo da História Ambiental, feito com o ferramental metodológico da História, da Ecologia e da Geografia, tem contribuído para uma análise integrada dos ecossistemas, que abarca tanto a sua dimensão humana (a história das populações que interagiram com a paisagem), como a dimensão física e biológica dos ecossistemas.

O papel da presença humana na formação da estrutura e funcionamento dos ecossistemas tem se tornado cada vez mais frequente em pesquisas ecológicas nas duas últimas décadas. ${ }^{2}$ Estes legados do passado, assim como aqueles ligados a eventos naturais, podem repercutir nos ecossistemas, controlar o funcionamento deles e persistir por centenas a milhares de anos, influenciando a estrutura da vegetação, a composição de espécies, a ciclagem de nutrientes, o fluxo da água e o clima. De forma cumulativa, esses legados vêm apresentando crescentes impactos globais nas funções ecológicas dos ecossistemas. ${ }^{3}$ No entanto, muitas vezes estão escondidos sob o véu de uma visão estática das paisagens, feita apenas a partir de sua configuração atual.

Em uma perspectiva histórica é evidente que a paisagem que nos chegou até hoje é produto das relações de populações com o seu ambiente. Nesse particular é conveniente lembrar que muitos pesquisadores ainda concebem os sistemas ecológicos como "naturais", desconectados das atividades humanas que se passaram em diversas escalas de tempo. Há, portanto, a necessidade de se incluir o legado da atividade humana como parte do enfoque ecológico nas investigações sobre a paisagem e, portanto, não se limitar a interpretar a sua estrutura e funcionamento a partir de um ponto de vista exclusivamente "natural". ${ }^{4}$

A Floresta Atlântica, extensa formação que ocorre em grande parte do litoral brasileiro, não é uma formação homogênea (Figura 1). Na região Sudeste ela é composta por três formações distintas: as florestas das planícies litorâneas, as de encosta e as de altitude. ${ }^{5}$ Outro ponto de destaque são os endemismos. O bioma apresenta uma das maiores taxas de endemismo do planeta $(40 \%)$, com aproximadamente 8.000 espécies de plantas endêmicas, 73 de pássaros, 160 de mamíferos, entre outras taxas. ${ }^{6}$ 
História da paisagem e paisagens sem história: a presença humana na Floresta Atlântica do Sudeste Brasileiro

Essa diversidade está ligada a uma grande heterogeneidade espacial, em função de diferentes latitudes, altitudes e usos históricos. Além disso, em função de usos anteriores diversos, principalmente a agricultura de subsistência, a grande maioria dos remanescentes é composta por florestas secundárias muito fragmentadas e submetidas a pressões diversas. São muito escassas áreas de floresta de encosta sem vestígio de usos anteriores; essas podem ser encontradas apenas em vertentes declivosas, em encosta com grande número de matacões ou em linhas de cumeadas. A maioria das demais áreas florestadas (principalmente o domínio da Floresta Ombrófila Densa Sub-montana) apresenta vestígios como baldrames de casa, fragmentos de carvão no solo, espécies exóticas ou escapadas de cultivo, explicando assim a ocorrência de vastas áreas de florestas secundárias. Essa situação, com poucas variações, se repete em numerosos trechos da Serra do Mar. No entanto, essas formações secundárias apresentam um impacto global bastante positivo, pois têm implicações no seqüestro de carbono, na biodiversidade regional e na estabilidade do solo. ${ }^{7}$

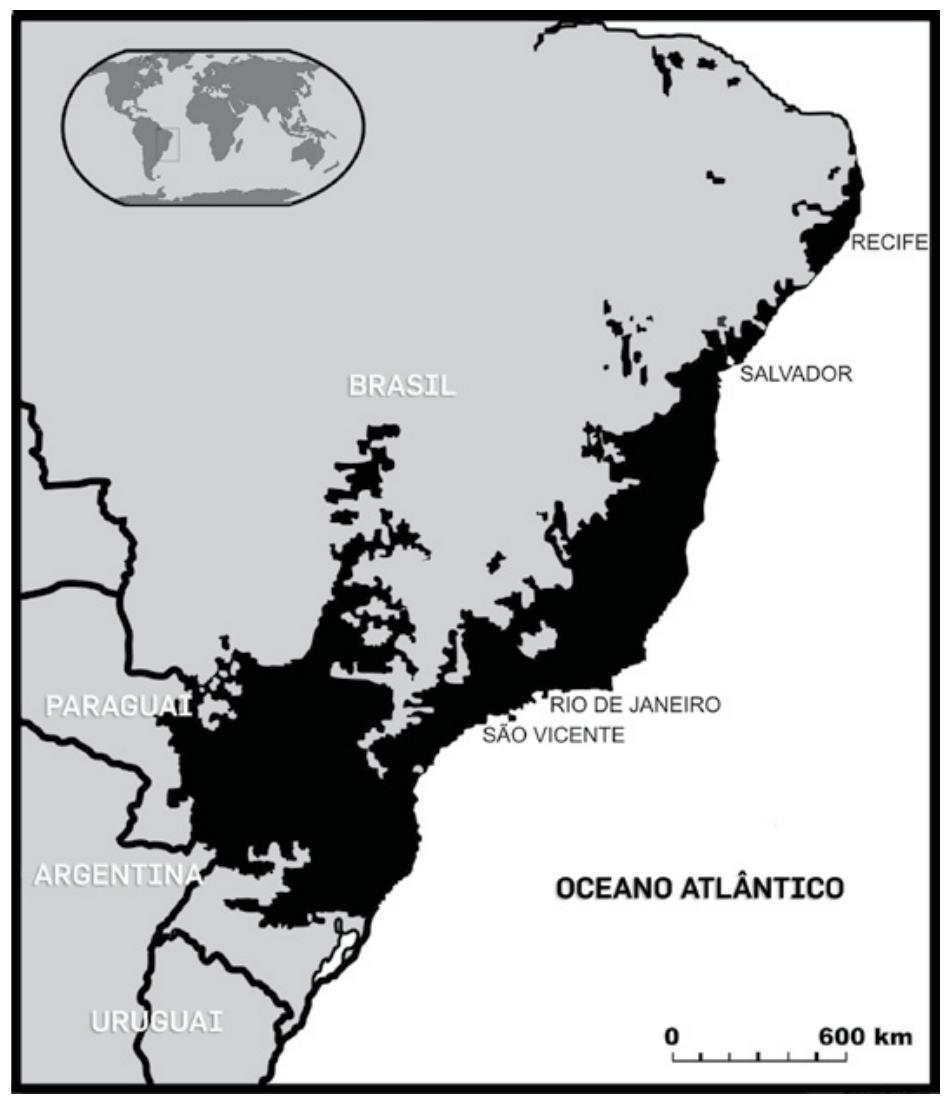

Figura 1 - Distribuição potencial do bioma da Mata Atlântica na costa brasileira. 
Na Floresta Atlântica a ocupação humana data de milhares de anos. No Estado do Rio de Janeiro foi encontrada uma datação de $2.920 \pm 70$ anos BP de carvão utilizado em uma urna funerária tupi-guarani. ${ }^{8}$ No entanto, na linha de costa referente à Mata Atlântica, a ocupação humana por habitantes dos sambaquis recua a 6.500 anos BP. Atualmente, essas populações não são mais percebidas como um bando nômade de coletores de moluscos, mas como pertencentes a uma complexa sociedade com elaborados rituais funerários e destaca-se a grandiosidade dos sambaquis como o resultado de um orquestrado trabalho social. ${ }^{9}$ Assim, um longo histórico de transformação de suas condições ambientais é resultante da forma com que suas populações - sejam elas compostas de sambaquieiros, de índios, de miscigenados, de imigrantes ou de afro-descendentes - interagiram e interagem com o ambiente. A Floresta Atlântica, tal como a conhecemos hoje, pode ser interpretada como um documento histórico que potencialmente evidencia e descreve - em numerosos de seus atributos - a resultante da interação de seres humanos com o ecossistema. ${ }^{10} \mathrm{~A}$ reconstrução da história da atividade humana sobre os ecossistemas pode se realizar sob diferentes enfoques e em diferentes escalas espaciais e temporais. ${ }^{11}$ No entanto, esses recortes devem levar em consideração o fato de que as florestas são percebidas como territórios, isto é, espaços vividos e apropriados pelas culturas que as utilizaram em diferentes épocas, portanto, socialmente divididos e manipulados. A busca pelas condições de existência física e os mecanismos culturais constituem os motores da apropriação, identificação e transformação dos espaços florestados. Mesmo após o abandono da atividade econômica, ao longo do tempo a sucessão ecológica desses usos deixa marcas, espacializa-se e sobrepõe-se sob a forma de paleoterritórios, entendidos como espacialização das resultantes ecológicas decorrentes do uso dos ecossistemas pelas diversas atividades sócio-econômicas que ocorreram neles. O paleoterritório constitui, portanto, a etapa antrópica dos processos bióticos e abióticos que condicionam o processo da regeneração das florestas, onde a cultura das chamadas populações tradicionais desempenha um papel determinante. ${ }^{12}$ Assim, o resgate da história desses usos superpostos dos espaços é de grande importância para o entendimento da dinâmica dos ecossistemas.

\section{FONTES DOCUMENTAIS E A TRANSFORMAÇÃO DA PAISAGEM DO BRASIL COLONIAL}

Para a compreensão das mudanças na composição dos ecossistemas, importa conhecer as perturbações - sejam elas naturais ou antropogênicas a que estiveram submetidos. Evidentemente não se pode tomar como um dado confiável que as atividades humanas e principalmente eventos ecológicos estejam significativamente documentados e disponíveis em registros históricos 
escritos. Urs Gimmi e Matthias Bürgi reportam uma dessas mal documentadas atividades com elevado potencial de impactos sobre os ecossistemas florestais: a coleta de serapilheira, um uso tradicional das florestas no cantão de Valais (Suíça). ${ }^{13}$

Para muitos casos da história da ocupação do espaço brasileiro - e em particular dos ecossistemas florestais - é disponível uma vasta documentação manuscrita que possibilita a reconstrução da história das atividades e ações de diversos grupos sociais e que redundaram na transformação da paisagem. Sendo constituída de inventários administrativos e "post-mortem", relatórios de produção, e congêneres, essa documentação é, geralmente, encontrada em arquivos públicos, cartórios, igrejas, fóruns ou associações diversas e permitem vincular, de várias formas, as atividades econômicas a formas de uso da Floresta Atlântica.

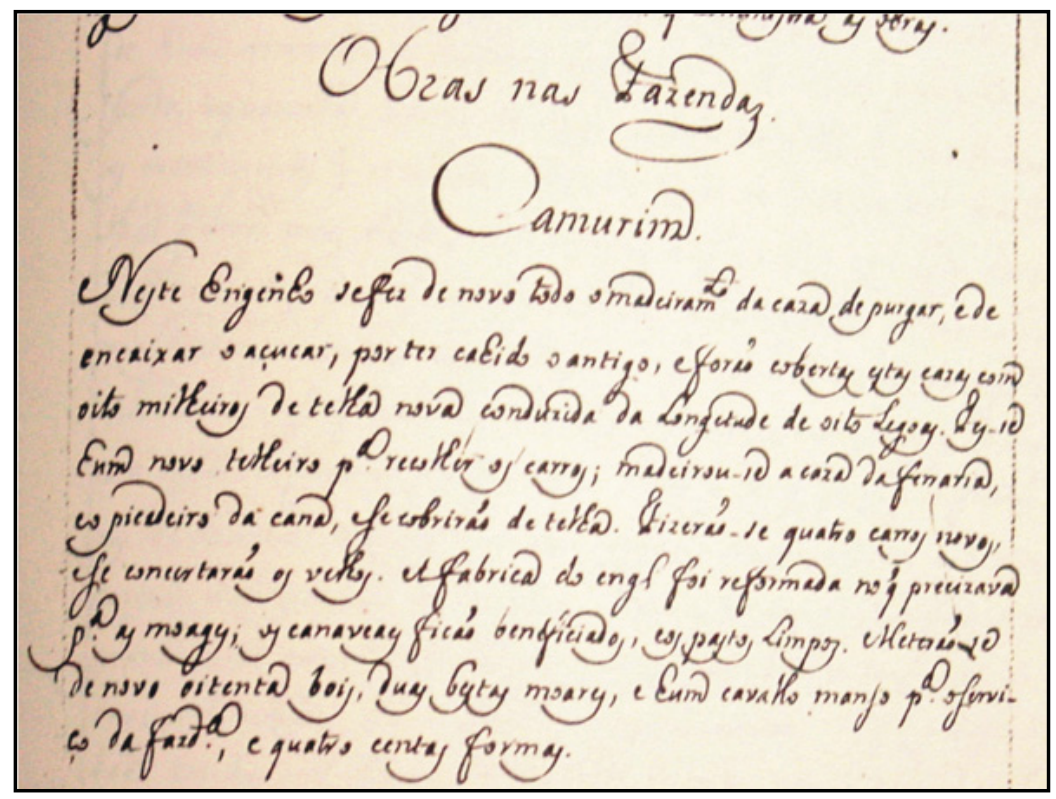

Figura 2 - Reprodução de Estado da Ordem de 1786, do mosteiro de São Bento, Rio de Janeiro, relativo ao Engenho de Camorim.

As ordens religiosas foram igualmente responsáveis por uma produção documental relevante para a compreensão dos processos de usos e transformações do bioma da Floresta Atlântica. Um exemplo são os Estados da Ordem, relatórios trienais acerca do estado material das posses do Mosteiro de São Bento, no Rio de Janeiro (Figura 2). Por meio dos dados sistematicamente organizados nesses Estados da Ordem foi possível a Engemann e colaboradores ${ }^{14}$ fazer a estimativa do consumo de lenha de um 
História da paisagem e paisagens sem história: a presença humana na Floresta Atlântica do Sudeste Brasileiro

engenho de propriedade da ordem, o Engenho de Camorim. Para atender ao consumo anual de lenha anual da safra de cana-de-açúcar desse engenho (4.200 $\mathrm{m}^{3}$ ), era necessário o abate de florestas da ordem de 4 a 21 hectares por ano. Para se ter idéia do impacto da atividade açucareira sobre a Floresta Atlântica, convém lembrar que, somente na Capitania do Rio de Janeiro, no início do século XVIII, existiam 131 engenhos em funcionamento. ${ }^{15}$

Além dessa documentação cartorial e eclesiástica, contam-se ainda como fontes impressas, no fundamental, os manuais agronômicos publicados nos séculos XVIII e XIX. Estes textos, por seu caráter técnico-pedagógico, trazem valiosas informações sobre as bases discursivas dos mecanismos econômicos com meio ambiente e dos processos de transformação da paisagem. Em sua maioria trazem ao público a dicotomia existente entre os conhecimentos agronômicos europeus e a sua adaptação à realidade tropical.

Ocorre ainda que nesses manuais, de acordo com o seu contexto histórico e as influências geradoras do pensamento de seus autores, as representações das bases dessa relação homem-natureza podem ser diametralmente opostas. ${ }^{16}$ É o que se pode ver na obra Cultura e Opulência do Brasil por suas Drogas e Minas, do Pe. André João Antonil, de 1711. ${ }^{17}$ É perceptível no discurso, embora estrangeiro e eclesiástico, mas plasmado na tradição da natureza exuberante e pródiga iniciada com Pero Vaz de Caminha, que a percepção do autor, certamente representativo de sua da época, é a das florestas como um recurso inexaurível:

O alimento do fogo é a lenha, e só o Brasil, com a imensidade dos matos que tem, podia fartar, como fartou por tantos anos, e fartará nos tempos vindouros, a tantas fornalhas, quantas são as que se contam nos engenhos da Bahia, Pernambuco e Rio de Janeiro, que comumente moem de dia e de noite, seis, sete, oito e nove meses do ano. ${ }^{16}$

Algumas décadas mais tarde, sob a influência das práticas agrícolas européias, de fronteiras agrícolas estreitas e já bastante consumidas, na obra O Fazendeiro do Brasil, do Frei José Mariano da Conceição Velloso (1798), fundada na busca pela modernização e aprimoramento técnico, pode ser encontrada uma outra percepção acerca do uso das florestas:

As matas são finitas. Quantos engenhos de açúcar não têm deixado de existir pela falta deste combustível? A Ilha do Governador, no Rio de Janeiro, foi chamada antigamente de sete engenhos; hoje tem apenas um, insignificante. Quantas fazendas se acham reduzidas a taperas, porque seus matos se converteram em sapezais e setais ${ }^{18}$ pelo errado princípio da 
História da paisagem e paisagens sem história: a presença humana na Floresta Atlântica do Sudeste Brasileiro

sua agricultura? [...] Cartago e Tróia não viram certamente maiores montes de cinzas quando foram arrasadas do que se vê nas roças do Brasil e com que se destroem essas importantíssimas e belíssimas matas atualmente. ${ }^{19}$

Em grande medida, a passagem da agricultura nômade praticada pelos índios para a agricultura permanente é uma introdução do colonizador europeu no Brasil. Essa mudança acarretou na perda de significativa parte da Floresta Atlântica e foi iniciada com o plantio sistemático de gêneros alimentícios, com destaque para o cultivo de exportação da cana-de-açúcar, praticado em larga escala e em regime de monocultura.

A implantação da monocultura e a redução da agricultura nômade não significaram que o uso da floresta tenha se reduzido, antes o contrário. $\mathrm{O}$ cultivo da cana era fundamentado em um sistema de alta taxa de desperdício, possível pela crença nos abundantes recursos de terra, floresta e trabalho. Por outro lado, o relativo baixo custo de alimentos, terras e trabalho é outro fator que contribuiu para a alta taxa de desperdício de recursos. ${ }^{20} \mathrm{O}$ uso e a conversão das florestas em terreno agrícola não eram apenas voltados para as grandes monoculturas como a cana de açúcar e o café. Além do espaço necessário ao cultivo desses produtos, muita terra era necessária para a implantação das roças de subsistência. Essas roças funcionavam como um verdadeiro tratado de paz entre senhores e escravos. Representavam para os primeiros um corte robusto em suas despesas de manutenção da escravaria e, para os segundos, a possibilidade de alguma independência econômica. ${ }^{21}$ Além disso, essas roças, por seu caráter periférico (e até clandestino, em certos casos) em relação à economia central (açúcar e posteriormente o café), passaram a se constituir como uma relevante atividade de sobrevivência de numerosos grupos étnicos excluídos ou precariamente incluídos no sistema econômico vigente. $\mathrm{Na}$ colônia, esta população rural livre de pequenos agricultores, roceiros, sitiantes, arrendatários e dependentes permaneceu, em grande parte, "sem rosto e sem nome". ${ }^{22}$ Essa forma de ocupação, feita principalmente no regime de derrubadaplantio-pousio, gerou extensas áreas de florestas secundárias, muitas delas o único testemunho que se dispõe da Floresta Atlântica.

Se, por um lado, essas roças geraram uma significativa transformação do bioma da Floresta Atlântica, por outro, muito pouco deixaram em termos de documentação acerca da história destas paisagens formadas. ${ }^{23}$ Dispõe-se, portanto, de documentação sobre a história do vencedor (o dono de engenho, o fazendeiro de café) e não sobre o vencido (o escravo, o índio). Sobre este, parte de sua história encontra-se inserida na paisagem que construíram.

Somente em tempos recentes, com o avanço da pesquisa histórica e etnográfica, ocorreu uma significativa produção bibliográfica trazendo 
História da paisagem e paisagens sem história: a presença humana na Floresta Atlântica do Sudeste Brasileiro

importantes subsídios à compreensão do processo de transformação ecológica da paisagem da Floresta Atlântica, seja pelo enfoque dos ecossistemas ou pela exploração de espécies faunísticas ou florísticas.

\section{MEMÓRIAS PERDIDAS E RECONSTRUIIDAS NA FLORESTA ATLÂNTICA}

Os diversos ordenamentos econômicos e espaciais que ocorreram na paisagem da Floresta Atlântica ao longo dos séculos não tiveram todos o mesmo sentido. Se a exploração da cana e do café apresentou características concentradoras, alguns grupos e economias periféricas tenderam, como visto, à dispersão espacial ao longo da Floresta Atlântica. Além das roças diretamente associadas ao sistema das monoculturas, uma grande parte da população interiorana vivia vinculada indiretamente a estas economias ou delas dependentes, compreendendo grupos de diversas origens culturais. O território da Floresta Atlântica foi, e em parte é, habitado por muitos desses grupos, hoje denominados genericamente como populações tradicionais, como as comunidades descendentes de etnias indígenas, pequenas populações amplamente miscigenadas, remanescentes de quilombos ou grupos descendentes de imigração mais recente. Embora seja extremamente complexo definir genericamente esses grupos, dada a sua diversidade cultural em função das múltiplas origens, pode-se usar um conceito amplo de população tradicional, para efeitos de estudo das suas resultantes ecológicas. ${ }^{24}$

Essas populações são consideradas como pequenos produtores que se constituíram desde o período colonial, freqüentemente nos interstícios das monoculturas e dos movimentos macro-econômicos. Em função da imensa diversidade cultural dessas populações, distintas resultantes ecológicas podem ser esperadas. Do ponto de vista empírico, é possível também identificar as populações tradicionais como aquelas que se baseiam no trabalho familiar, visando principalmente ao próprio sustento, embora normalmente estejam vinculadas aos mercados locais. Embora existam opiniões conflitantes a esse respeito ${ }^{25}$, um aspecto específico dessas comunidades é a utilização das chamadas tecnologias de baixo impacto, como o extrativismo, a pesca e a lavoura de pequena escala. São ainda características particularmente importantes na definição destes grupos: a) conhecimento dos recursos naturais, que se reflete na elaboração de estratégias de uso e de manejo, geralmente transferido e geração a geração; b) noção de território ou espaço onde o grupo se reproduz econômica e socialmente; e c) moradia e ocupação desse território por várias gerações. ${ }^{26}$

A essas características pode-se acrescentar como um ponto comum à grande maioria desses grupos culturais a virtual inexistência de documentação 
História da paisagem e paisagens sem história: a presença humana na Floresta Atlântica do Sudeste Brasileiro

cartorial, eclesiástica, jurídica - ou quaisquer das modalidades tradicionais de documentação - acerca de suas raízes e principalmente sobre a forma de ocupação de seus territórios. Restam-nos os trabalhos de caráter etnográfico e de construção de fontes orais como uma significativa exceção a esse quadro. Exceto essas pesquisas, a grande maioria das informações que se dispõe para cada grupo provém, quando existente, da tradição oral por parte da população mais idosa, portanto, em vias de desaparecer. Pouca informação acerca de suas técnicas é transmitida para as novas gerações.

Um ponto em comum faz convergir a quase totalidade desses grupos culturais: a agricultura. Em função das características ecológicas das florestas tropicais e, em particular, da Floresta Atlântica, os conhecimentos produzidos por essas populações sofrem uma verdadeira seleção de práticas e o resultado disso é, frequentemente, uma convergência entre processos culturais de origem bastante distantes entre si, no que se refere ao tempo ou ao espaço. Populações seculares ou milenares atuando sobre um mesmo ecossistema acabam por promover a consolidação de um conjunto de conhecimentos acerca do seu manejo, independente de sua origem cultural. ${ }^{27}$

O melhor exemplo é a agricultura de coivara, praticada com diferenças mínimas em quase todo o território brasileiro em diferentes épocas. O sucesso desse método é devido, em grande parte, às técnicas culturais utilizadas para se contornar o problema da infertilidade do solo das áreas onde ele é praticado. A maioria dos solos da Floresta Atlântica é deficiente em fósforo. No entanto, essas pequenas quantidades participam de um circuito quase fechado, sendo suficientes para prevenir a sua deficiência. A ação do fogo é, portanto, fundamental para este tipo de empreendimento, ao transferir para o solo o fósforo e demais nutrientes acumulados na biomassa florestal. Embora esses sistemas agrícolas possam parecer primitivos, ineficientes e ambientalmente inadequados, sob circunstâncias apropriadas podem ser altamente produtivos em termos de energia, relativamente neutros nos seus efeitos ecológicos no longo prazo e sofisticados nas suas adaptações e estratégias ecológicas. ${ }^{28}$

\section{HISTÓRIA DA PAISAGEM E HISTÓRIA NA PAISAGEM}

Um conceito bastante adequado ao entendimento da relação sociedade $\mathrm{x}$ natureza é o de paisagem. Polissêmico por origem, a paisagem pode também ser considerada como um uma estrutura espacial que resulta da interação entre os processos naturais e atividades humanas. Ao associar ações passadas e presentes, a paisagem constitui-se uma categoria do espaço que é um produto da co-evolução das sociedades humanas e do meio natural ${ }^{29}$ ou ainda, uma manifestação espacial da relação homem-ambiente..$^{30}$ 
História da paisagem e paisagens sem história: a presença humana na Floresta Atlântica do Sudeste Brasileiro

A ação das diversas sociedades modela o ambiente por meio do estabelecimento de múltiplos territórios. A vegetação também tem uma dinâmica própria, trazendo também traços do passado. As formas de influência das atividades humanas em fluxos e processos dos ecossistemas e paisagens são múltiplas, existindo um gradiente que vai desde ecossistemas quase naturais ou pouco alterados, até os ecossistemas que são completamente antropogênicos. Os solos são o componente do ecossistema com a "memória" mais longa de distúrbios, mas a fauna e a flora igualmente refletem por longo tempo depois de passados os impactos humanos. ${ }^{31}$

Em muitas partes do globo, marcas antigas da atividade humana sobre os ecossistemas continuam influenciando os padrões e processos ecológicos contemporâneos. Essas marcas podem ser evidenciadas por, pelo menos, dois tipos de vestígios. $\mathrm{O}$ primeiro diz respeito à cultura material de povos que habitaram uma determinada área no passado. Em locais onde a sucessão ecológica resultou na formação de florestas secundárias, os vestígios arqueológicos mais freqüentes são baldrames de antigas casas, restos de fornos de pedra, antigas carvoarias, caminhos calçados com pedras e, mais raramente, sambaquis. A maioria desses vestígios está associada à presença de fragmentos de carvão. Nesse particular, a antracologia - ciência que abrange o estudo e a interpretação dos restos de madeira carbonizados - representa uma ferramenta de destaque para a compreensão das técnicas de transformação utilizadas. ${ }^{32}$ Esse estudo é possível porque a estrutura anatômica da madeira se preserva perfeitamente após a carbonização. Assim, a informação antracológica permite a um tempo o resgate da composição e da estrutura do ecossistema, assim como aspectos ligados às técnicas empregadas pelas populações passadas. A segunda fonte de vestígios sobre a história de uma floresta é dada por aspectos menos evidentes como a composição, a estrutura ou a funcionalidade dos ecossistemas.

Como visto anteriormente, a Floresta Atlântica, tal como a conhecemos hoje, pode ser considerada como um documento histórico que evidencia e descreve a resultante ecológica da interação de seres humanos com o ecossistema. Muitos trabalhos vêm demonstrando que florestas tidas como primárias podem ter sido intensamente manejadas pelo homem no passado, direta ou indiretamente. ${ }^{33} \mathrm{Um}$ dos exemplos que melhor demonstra como a ação antrópica pode estar presente e, portanto, reconhecida, é por meio do estudo de roças abandonadas por populações tradicionais, particularmente caiçaras no Sudeste Brasileiro. A cultura caiçara é característica do litoral dos estados do Rio de Janeiro, São Paulo e Paraná e é baseada na pesca e em roças de subsistência. Em termos culturais, surgiu da miscigenação genética e cultural de portugueses com populações indígenas do litoral, sofrendo mais tarde alguma influência de grupos afro-descendentes. A definição dessa cultura, entre outros aspectos, deve-se ao tipo de vida mais fechada que se desenvolveu 
História da paisagem e paisagens sem história: a presença humana na Floresta Atlântica do Sudeste Brasileiro

no litoral, relativamente isolado do mundo de fora em termos de produtos e influências. ${ }^{34}$ No Sudeste Brasileiro, extensas áreas utilizadas preteritamente por caiçaras para cultivos de subsistência geraram florestas secundárias em diversos estágios de regeneração, alterando consideravelmente a composição, a estrutura e a funcionalidade originais da Floresta Atlântica. ${ }^{35}$

Com relação às marcas deixadas na paisagem pelas antigas roças e moradias, numerosos aspectos podem ser detectados nos atributos da floresta que se sucede ao abandono dos plantios. A respeito da composição florística desses paleoterritórios, a presença de espécies exóticas introduzidas ou, ainda, de nativas domesticadas, constitui uma das interações mais evidentes deixadas pelas populações passadas nas florestas que se regeneram. Na verdade, o processo de domesticação de espécies constitui um continuum do investimento humano na seleção e na manipulação ambiental..$^{36} \mathrm{~A}$ domesticação da paisagem constitui um processo consciente pelo qual a manipulação humana produz mudanças nos processos ecológicos da paisagem e na demografia de suas plantas e animais, resultando em uma paisagem mais produtiva e adequada às necessidades das populações. Assim, a densidade populacional humana em uma dada área se correlaciona com a capacidade de suporte da paisagem domesticada, que é determinada pela interação entre o ambiente físico e as necessidades humanas. ${ }^{37}$

O processo de domesticação da paisagem empreendido por populações passadas pode ser avaliado pelo grande número de espécies exóticas, comumente encontradas em tratos de Floresta Atlântica secundária. Introduzidas ou manejadas com as mais diversas finalidades (medicinais, rituais, alimentares), mais do que um simples vestígio material de populações passadas, essas espécies podem desempenhar uma importante resultante ecológica, seja na dinâmica das populações nativas, seja na ciclagem de nutrientes ou, ainda, na oferta de recursos para a fauna. Algumas dessas espécies históricas podem inclusive se tornar invasoras dos atuais remanescentes florestais. As informações da tabela 1 foram obtidas com base em observações de campo e em bibliografia específica. ${ }^{38}$ 
Revista Esboços, Florianópolis, v. 18, n. 25, p. 9-31, ago. 2011

História da paisagem e paisagens sem história: a presença humana na Floresta Atlântica do Sudeste Brasileiro

Tabela I - Espécies exóticas de origem histórica encontradas em florestas secundárias da região Sudeste Brasileira

\begin{tabular}{|c|c|c|c|c|}
\hline nome vulgar & espécie & utilidade & proveniência & $\begin{array}{l}\text { reprodução / } \\
\text { propagação }\end{array}$ \\
\hline abacate & Persea americana Mill. & $\begin{array}{l}\text { alimentar / } \\
\text { medicinal }\end{array}$ & $\begin{array}{l}\text { plantios } \\
\text { abandonados }\end{array}$ & $\begin{array}{l}\text { sexuada; } \\
\text { germinação } \\
\text { espontânea }\end{array}$ \\
\hline abre-caminho & Lygodium volubile Sw. & ritual & nativa & Vegetativa \\
\hline alfavaca & Ocimum gratissimum L. & $\begin{array}{l}\text { condimento } \\
\text { e ritual }\end{array}$ & $\begin{array}{l}\text { escapada de } \\
\text { cultivo }\end{array}$ & $\begin{array}{l}\text { sexuada e } \\
\text { vegetativa }\end{array}$ \\
\hline bambu & $\begin{array}{l}\text { Bambusa vulgaris Schrad. } \\
\text { ex J.C. Wendl. }\end{array}$ & $\begin{array}{l}\text { construção } \\
\text { / cestaria }\end{array}$ & $\begin{array}{l}\text { plantios } \\
\text { abandonados }\end{array}$ & Vegetativa \\
\hline banana & Musa x paradisiaca L. & alimentar & $\begin{array}{l}\text { escapada } \\
\text { de cultivo } \\
\text { / plantios } \\
\text { abandonados }\end{array}$ & $\begin{array}{l}\text { exclusiva- } \\
\text { mente } \\
\text { vegetativa }\end{array}$ \\
\hline beijo-de-frade & $\begin{array}{l}\text { Impatiens walleriana } \\
\text { Hook. f. }\end{array}$ & ornamental & $?$ & $\begin{array}{l}\text { sexuada; } \\
\text { germinação } \\
\text { espontânea }\end{array}$ \\
\hline cabaceira & Crescentia cujete L. & $\begin{array}{l}\text { uso } \\
\text { doméstico }\end{array}$ & $\begin{array}{l}\text { plantio } \\
\text { intencional }\end{array}$ & $\begin{array}{l}\text { sexuada; } \\
\text { germinação } \\
\text { não } \\
\text { espontânea }\end{array}$ \\
\hline café & Coffea arabica L. & alimentar & antigos cultivos & $\begin{array}{l}\text { sexuada; } \\
\text { germinação } \\
\text { espontânea }\end{array}$ \\
\hline caimito & Chrysophyllum cainito L. & alimentar & $\begin{array}{l}\text { antigos } \\
\text { pomares }\end{array}$ & Sexuada \\
\hline calanchoe & $\begin{array}{l}\text { Kalanchoe waldheimi } \\
\text { Raym.-Hamet \& } \\
\text { H. Perrier }\end{array}$ & $\begin{array}{l}\text { medicinal e } \\
\text { ornamental }\end{array}$ & $\begin{array}{l}\text { plantios } \\
\text { abandonados }\end{array}$ & Vegetativa \\
\hline cantaria & $\begin{array}{l}\text { Oeceoclades maculata } \\
\text { Lindl. }\end{array}$ & ritual & $\begin{array}{l}\text { escapada de } \\
\text { cultivo }\end{array}$ & Sexuada \\
\hline
\end{tabular}


Revista Esboços, Florianópolis, v. 18, n. 25, p. 9-31, ago. 2011

História da paisagem e paisagens sem história: a presença humana na Floresta Atlântica do Sudeste Brasileiro

\begin{tabular}{|c|c|c|c|c|}
\hline nome vulgar & espécie & utilidade & proveniência & $\begin{array}{l}\text { reprodução / } \\
\text { propagação }\end{array}$ \\
\hline chuchu & $\begin{array}{l}\text { Sechium edule (Jacq.) } \\
\text { Sw. }\end{array}$ & alimentar & $\begin{array}{l}\text { escapada de } \\
\text { cultivo }\end{array}$ & $\begin{array}{l}\text { sexuada; } \\
\text { germinação } \\
\text { espontânea }\end{array}$ \\
\hline $\begin{array}{l}\text { comigo- } \\
\text { ninguém-pode }\end{array}$ & $\begin{array}{l}\text { Dieffenbachia picta } \\
\text { Schott. }\end{array}$ & ritual & $\begin{array}{l}\text { plantios } \\
\text { abandonados }\end{array}$ & Vegetativa \\
\hline cana-do-brejo & Costus spiralis Rosc. & medicinal & $\begin{array}{l}\text { escapada de } \\
\text { cultivo }\end{array}$ & Vegetativa \\
\hline $\begin{array}{l}\text { espada-de- } \\
\text { são-jorge }\end{array}$ & $\begin{array}{l}\text { Sansevieria trifasciata } \\
\text { Prain }\end{array}$ & ritual & $\begin{array}{l}\text { plantios } \\
\text { abandonados }\end{array}$ & Vegetativa \\
\hline jaqueira & $\begin{array}{l}\text { Artocarpus heterophyllus } \\
\text { Lam. }\end{array}$ & $\begin{array}{l}\text { alimentar / } \\
\text { madeira }\end{array}$ & $\begin{array}{l}\text { antigos } \\
\text { pomares; }\end{array}$ & $\begin{array}{l}\text { sexuada; } \\
\text { germinação } \\
\text { espontânea }\end{array}$ \\
\hline $\begin{array}{l}\text { laranja-da- } \\
\text { terra }\end{array}$ & Citrus aurantium L. & alimentar & antigos quintais & $\begin{array}{l}\text { sexuada; } \\
\text { germinação } \\
\text { não } \\
\text { espontânea }\end{array}$ \\
\hline limão-galego & $\begin{array}{l}\text { Citrus aurantifolia } \\
\text { (Christem.) Swingle }\end{array}$ & alimentar & $\begin{array}{l}\text { antigos } \\
\text { pomares }\end{array}$ & $\begin{array}{l}\text { sexuada; } \\
\text { rebrota de } \\
\text { "cavalo" de } \\
\text { enxertias }\end{array}$ \\
\hline lírio-do-brejo & $\begin{array}{l}\text { Hedychium coronarium } \\
\text { J. König }\end{array}$ & $\begin{array}{l}\text { medicinal / } \\
\text { ritual }\end{array}$ & $?$ & $\begin{array}{l}\text { sexuada e } \\
\text { vegetativa; } \\
\text { germinação } \\
\text { espontânea }\end{array}$ \\
\hline mandioca & Manihot esculenta Crantz & alimentar & $\begin{array}{l}\text { escapada de } \\
\text { cultivo }\end{array}$ & $\begin{array}{l}\text { vegetativa } \\
\text { e sexuada } \\
\text { em roças } \\
\text { abandonadas; } \\
\text { germinação } \\
\text { espontânea }\end{array}$ \\
\hline mexerica & Citrus deliciosa Ten. & alimentar & antigos quintais & $\begin{array}{l}\text { sexuada; } \\
\text { germinação } \\
\text { espontânea }\end{array}$ \\
\hline trapoeraba & $\begin{array}{l}\text { Tradescantia zebrina } \\
\text { Hort. ex Bosse }\end{array}$ & ornamental & $\begin{array}{l}\text { plantios } \\
\text { abandonados }\end{array}$ & Vegetativa \\
\hline
\end{tabular}


Geralmente, as espécies acima permanecem nas florestas secundárias com baixa ou nula capacidade de expansão de suas populações, com a possível exceção da jaqueira e do cafeeiro, que podem passar à condição de invasoras florestais devido à sua alta capacidade de recrutamento. Na grande maioria dos fragmentos florestais do vale do médio Rio Paraíba do Sul, nos estados de Rio de Janeiro e São Paulo, por onde passaram os cultivos de café do século XIX, ocorre a presença constante de plântulas de café (exatamente da variedade bourbon, usada à época colonial). O café nos fragmentos dessa região se tornou uma invasora florestal dominando o sub-bosque, na maioria das vezes com recrutamento vigoroso e superior ao das demais espécies nativas presentes.

Com referência à mandioca, as capoeiras frequentemente abrigam remanescentes da cultura da mandioca (Manihot esculenta). Ao serem abandonados os cultivos, a mandioca muda da reprodução vegetativa (feita pelos caiçaras por meio de pedaços de caule, as manivas) para a reprodução sexuada, o que representa papel fundamental para a manutenção da diversidade genética das suas etno-variedades. ${ }^{39}$

Outro ponto importante na "leitura" da paisagem gerada por populações tradicionais no manejo da Floresta Atlântica diz respeito ao incremento do número de espécies ao longo do tempo relativo à sucessão ecológica. Ou seja, do ponto de vista da diversidade, como é a paisagem gerada por antigas roças caiçaras?

A Figura 3 apresenta uma relação entre número de espécies versus idade de florestas secundárias. Tratam-se de dados (primários ou secundários) obtidos de trabalhos feitos em vários locais da costa sudeste brasileira em territórios caiçaras ${ }^{40}$ feitos em áreas submetidas a roças e com idade de abandono situada no intervalo de 4 a 120 anos, realizados com metodologias comparáveis. A análise da associação entre o número de espécies e a idade sucessional, isto é, a idade da floresta após o abandono, se mostrou significativa e positiva $\left(\mathrm{r}^{2}\right.$ $=0,351 ; \mathrm{F}=16,733 ; p<0,01)$. Essa análise demonstrou que o número de espécies é um caráter preditivo da idade sucessional das áreas.

O comportamento médio apresentado nesses estudos evidencia uma relativa previsibilidade no aumento do número de espécies arbóreas ao longo do tempo, o que permite supor que o incremento de espécies no tempo constitui um indicador da idade. Liebsdch e colaboradores, ao estudarem a ocorrência de cerca de 400 espécies em florestas de distintas idades sucessionais na Floresta Atlântica, encontraram também uma relação positiva e significativa entre idade do fragmento e riqueza de espécies, com o incremento da proporção de espécies de dispersão animal assim como o número de espécies de sub-bosque. ${ }^{41}$ No entanto, há que se destacar que, do ponto de vista da composição, são múltiplas as possibilidades de trajetórias sucessionais, estruturais e florísticas, o que redunda na não previsibilidade do processo sucessional no que se refere à 
História da paisagem e paisagens sem história: a presença humana na Floresta Atlântica do Sudeste Brasileiro

sua composição. ${ }^{42}$ Dentre os fatores que condicionam essa multiplicidade de trajetórias, destaca-se a forma de uso pretérito feito pelas populações passadas.

\section{Dados e reta de regressão}

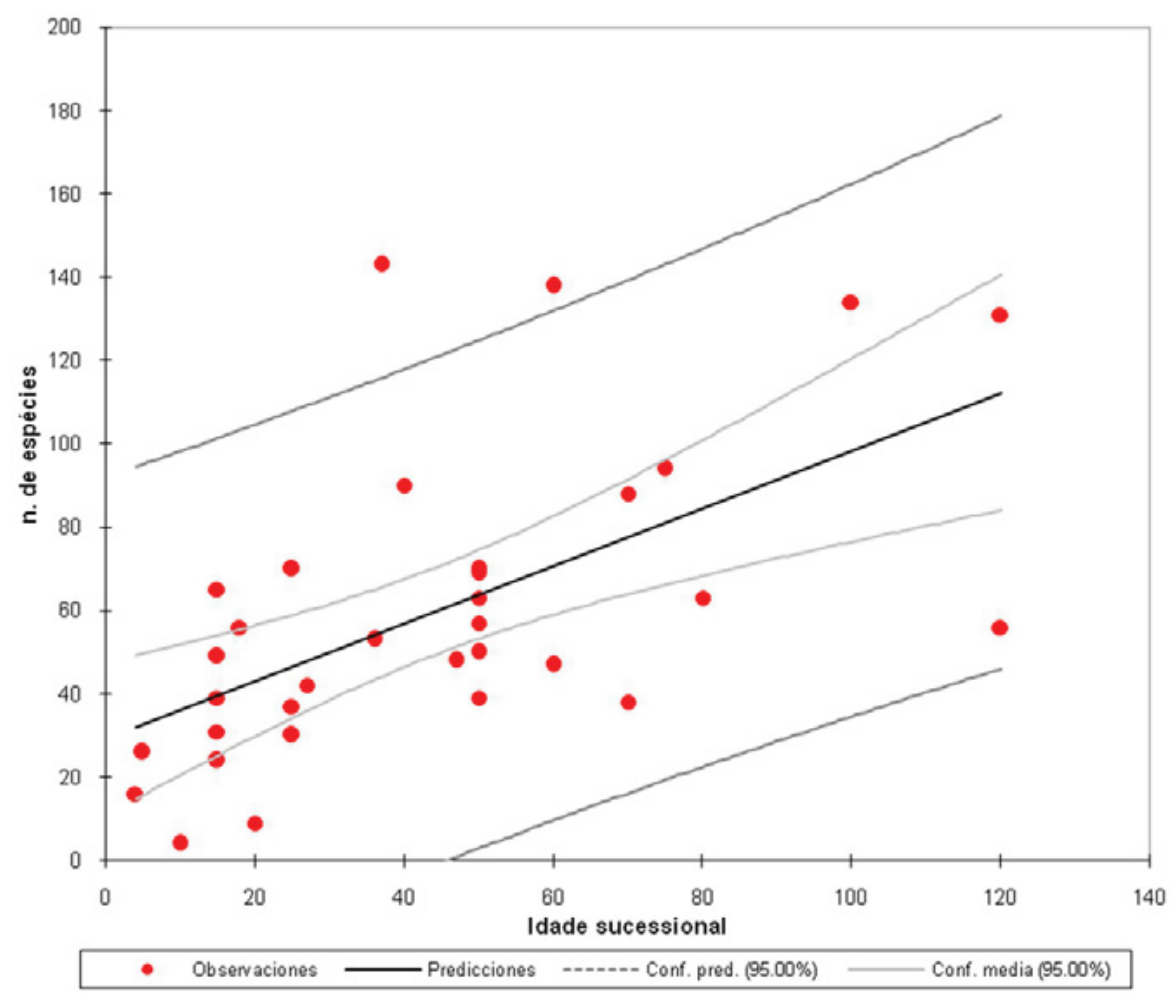

Figura 3 - Relação entre o incremento no número de espécies arbóreas e o tempo de abandono de roças na região sudeste.

Outra forma da interpretação das paisagens geradas pelo manejo de populações tradicionais na Floresta Atlântica diz respeito à funcionalidade do ecossistema. Essa é compreendida como as interações entre os fluxos de energia e matéria dentro e entre os componentes do ecossistema, mediadas pelo tempo e pelo fator antrópico. Para esse atributo, a ação humana desempenha um papel bastante particular na ciclagem de nutrientes da Floresta Atlântica. Embora não seja possível se descrever uma "típica floresta tropical", face às grandes variações que lhe são inerentes - notadamente na sua estrutura e composição existe uma tendência geral que aponta a disponibilidade de nutrientes como um fator de natureza crítica para o funcionamento desses ecossistemas. A pobreza 
de nutrientes estocados no solo de vastas áreas de Floresta Atlântica constitui um determinante que levou ao desenvolvimento de mecanismos que possibilitam a sobrevivência da comunidade como um todo por meio da minimização de perdas por processos erosivos. Esses mecanismos de sustentabilidade funcional constituem um conjunto de estratégias e estruturas de espécies individuais que, em conjunto, minimizam perdas e otimizam a captura das entradas de nutrientes. A serapilheira (isto é, a camada de folhas e galhos que cobre o solo florestal) consiste em um compartimento acumulador, onde todos os elementos bióticos e abióticos do ecossistema estão potencialmente representados, sendo, portanto, a sua composição química um reflexo do sistema. A maioria dos nutrientes da serapilheira não é lixiviada para o solo, mas transferida diretamente para as raízes localizadas no topo do solo e na camada de serapilheira, constituindo a chamada "ciclagem direta". ${ }^{43}$ Uma das formas de se mensurar a funcionalidade é pelo monitoramento da produção de serapilheira, bem como o seu estoque sobre o solo. Estudo conduzido na Ilha Grande (RJ) acompanhou, pelo prazo de dois anos, a produção e o estoque de serapilheira; os resultados encontramse na Figura $4 .{ }^{44}$

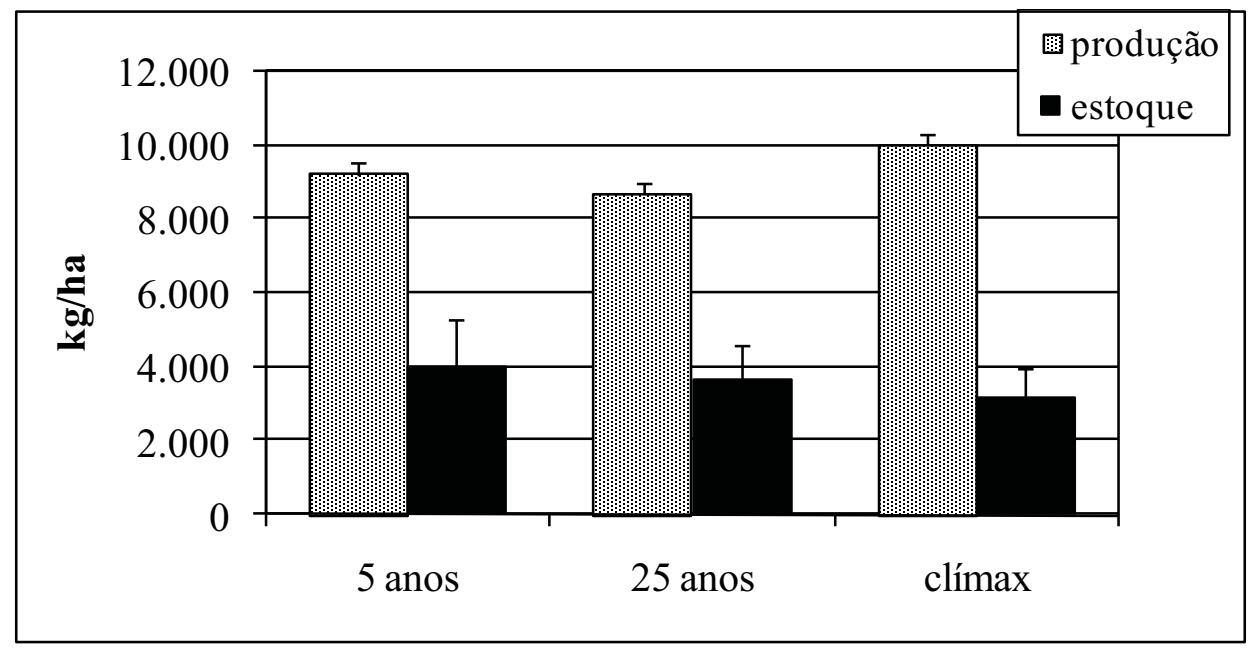

Figura 4 - Serapilheira produzida e estocada em três diferentes áreas da Ilha Grande, RJ. As duas primeiras áreas tratam-se de antigas roças de caiçaras. As linhas verticais representam o desvio padrão.

Nesse caso não foram encontradas diferenças significativas entre as diferentes idades, tanto no que se refere à produção quanto à acumulação de serapilheira sobre o solo. O manejo efetuado pelos caiçaras nas florestas em estágio inicial e médio de regeneração contribuiu para que a funcionalidade no sistema produtor/decompositor de serapilheira destas fosse semelhante a 
de um sistema maduro. Assim, o tempo de recomposição do sistema produtor da serapilheira, bem como a dinâmica de sua decomposição permite supor que a recuperação funcional do sistema não tem na composição das espécies presentes uma condição primordial, e sim no desenvolvimento dos mecanismos de captura e conservação de nutrientes. Isso nos permite postular que os aspectos funcionais têm maior importância para a manutenção dos fluxos de nutrientes e energia do que a riqueza de espécies. Assim, sob este ponto de vista funcional, o sistema produtor de serapilheira da Floresta Atlântica não parece evidenciar aspectos ligados ao tempo.

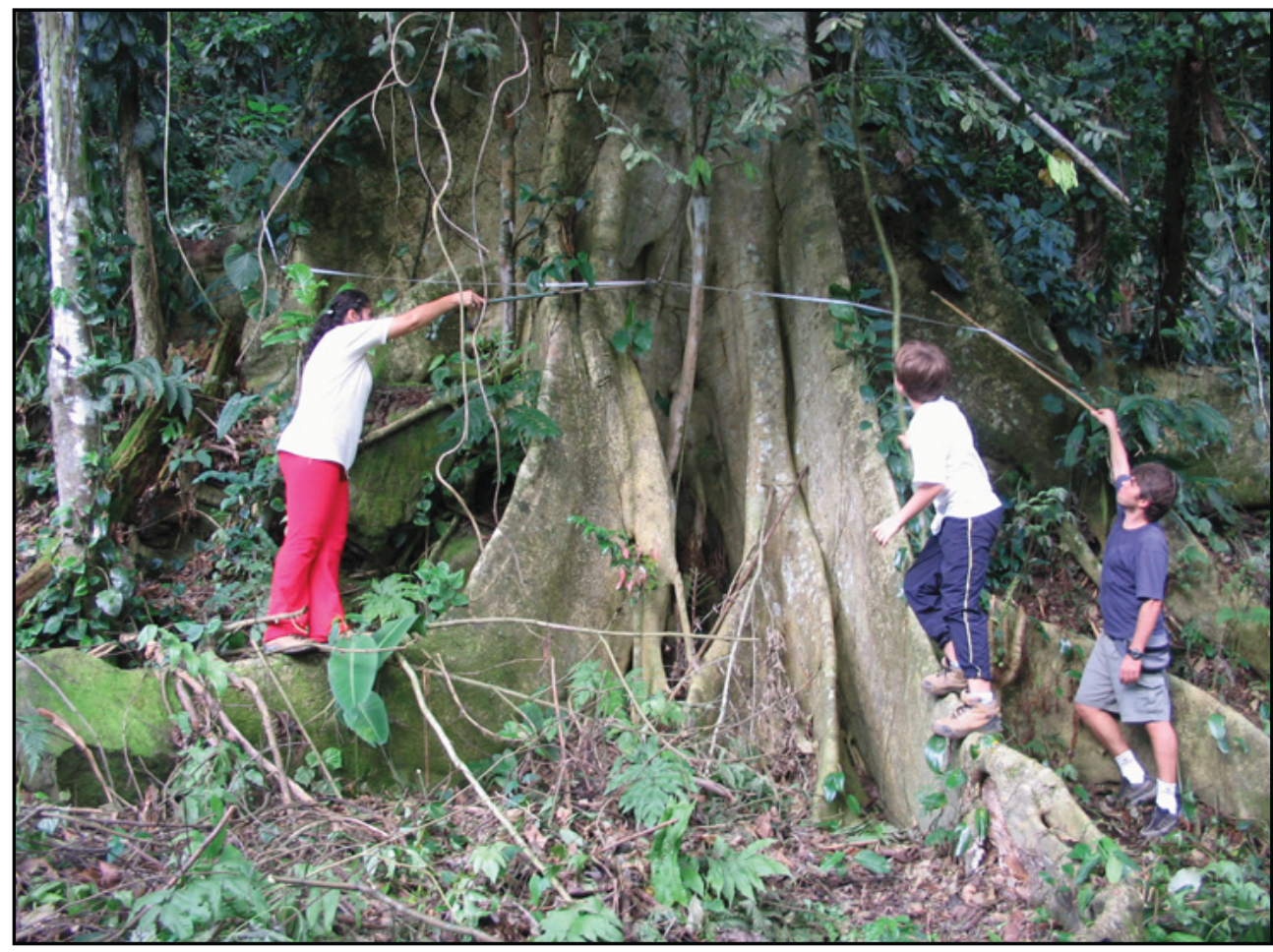

Figura 5 - Exemplar centenário de Ficus glabra encontrado em área de floresta secundária localizada no Sertão de Mambucaba, município de Angra dos Reis, RJ.

Ainda sob o enfoque da estrutura destas florestas secundárias, uma marca significativa na paisagem diz respeito à sua dimensão não-material. As figueiras centenárias da Floresta Atlântica constituem um caso exemplar desse componente da paisagem. Elas pertencem a várias espécies do gênero Ficus (da família das moráceas) e são preservadas do corte por ocasião da derrubada empreendida por populações interioranas quando da abertura de suas roças em 
áreas de Floresta Atlântica. Reconhecida em diversas tradições culturais como uma árvore que possui exemplares de elevado porte, alguns por apresentarem copas frondosas que podem abrigar muitos animais, a figueira, na cultura judaico-cristã, simboliza a casa de Deus na natureza e, portanto, uma das moradas do sagrado na floresta no inconsciente coletivo destas populações. ${ }^{45}$ Ainda de acordo esta autora, na tradição afrodescendente brasileira - por sua vez uma confluência de pelo menos quatro tradições ancestrais africanas -, a figueira ocupa o lugar de uma espécie africana - Clorophora excelsa - não encontrável no Brasil para representar um deus-árvore: o Iroko. A esse respeito, um fato interessante ocorreu com a vinda dos rituais religiosos do candomblé do continente africano para o Brasil. Aqui, algumas figueiras (Ficus glabra, $F$. gomelleira, $F$. cyclophylla ou ainda $F$. adhantifolia) substituem a morácea africana nos ritos do candomblé, mas a designação iroko permaneceu a mesma, sendo suas folhas utilizadas em rituais de iniciação. ${ }^{46}$ Muito possivelmente este arquétipo, presente em várias culturas, trouxe como resultante cultural a preservação de seus exemplares nos territórios e paleoterritórios ocupados por diversas populações tradicionais do Sudeste brasileiro. Assim, é bastante freqüente na paisagem da Floresta Atlântica a presença de exemplares adultos de grandes proporções de árvores pertencentes ao gênero Ficus em trechos de florestas secundárias da região sudeste brasileira, particularmente naquelas sob influência de roças caiçaras (Figura 5).

Geralmente se destacam dos demais indivíduos do componente arbóreo dessas formações pelo elevado diâmetro de caule e, em segundo lugar, pela sua altura total. Em síntese, a biomassa desses exemplares quase sempre supera, em muito, a dos demais componentes arbóreos dessas formações secundárias. ${ }^{47}$ A manutenção desses exemplares de figueiras ao longo dos ciclos uso da paisagem pelas populações passadas redunda em possíveis resultantes ecológicas e biogeográficas. Representam, particularmente, um recurso significativo para a fauna local, tendo sido observados forrageando seus frutos o papagaio chauá (Amazona rodocorytha), o tucano (Ramphastos vitellinus ariel), araçarí (Selenidera maculirostris), o macaco-bugio (Alouatta fusca), o macaco-prego (Cebus apeela), o coati (Nasua nasua), o caxinguelê (Sciurus aestuans) e outros. Essa dimensão imaterial do paleoterritório, que se traduz em resultantes ecológicas concretas, evidencia uma parte do largo espectro de ações de manejo dos ecossistemas por parte de populações tradicionais. As figueiras centenárias da Mata Atlântica constituem, portanto, um caso exemplar desse tipo de componente das paisagens constituídas por florestas secundárias utilizadas preteritamente por populações tradicionais. Preservadas do corte por ocasião da derrubada para implantação de suas roças, essas passam a assumir a condição de verdadeiros marcos culturais. No sentido cultural, tal fato pode estar evocando um aspecto simbólico da paisagem, ao expressar crenças, 
História da paisagem e paisagens sem história: a presença humana na Floresta Atlântica do Sudeste Brasileiro

valores e mitos de uma população. Essa dimensão imaterial do paleoterritório, que se traduz em resultantes ecológicas concretas, traz à tona o largo espectro de ações de manejo dos ecossistemas por parte de populações tradicionais.

\section{CONSIDERAÇÕES FINAIS}

Dentre as dimensões de estudos como o que estamos a apresentar é possível que duas se destaquem. Em primeiro lugar, o alargamento da compreensão de populações cujos registros escritos são por demais escassos e as tradições orais estão se fenecendo, ou já se extinguiram com a própria população. Em segundo, temos uma releitura da idéia de floresta intocada e de sua representação como valor.

Um ponto de destaque é que a grande maioria dos remanescentes florestais de Floresta Atlântica localiza-se justamente sobre territórios ou paleoterritórios destas populações periféricas. Em grande parte estes se tratam de resultantes ecológicas de um sistema cultural de manejo da floresta. Por outro lado, o sistema econômico central (as monoculturas da cana-de-açúcar, do café e a pecuária) gerou extensas áreas desflorestadas no território da Floresta Atlântica.

Agregar fontes novas aos estudos de populações desaparecidas, ou cuja cultura foi de tal sorte transformada pelo contato com os mecanismos modernizadores da civilização industrial, que hodiernamente suas bases originais se tornaram quase irreconhecíveis, representa um potencial benefício para o estudo dessas populações em questão. Acrescenta também à história $\mathrm{e}$ às ciências sociais e ambientais um caminho de análise que procura integrar a dimensão humana e ecológica nos ecossistemas. Propõe-se, neste trabalho, tanto um mecanismo para o estudo das populações que tratamos por tradicionais, quanto a qualquer conjunto social que tenha deixado marcas duradouras no ecossistema por ele manipulado. Ainda que com limites, traços culturais relevantes subsistem como resultantes ecológicas na floresta construída e reconstruída. Assim, por intermédio dessas marcas culturais e históricas, chegase a um caminho que possibilita a compreensão dos processos ecológicos que atuam no presente.

Por outro lado, busca-se romper com o romantismo, por vezes quase panfletário, do mito da floresta intocada como um valor absoluto. Desse modo, considera-se a possibilidade da existência de uma floresta-cultura, em detrimento da permanente busca do intocado, como portador de uma pureza quase mítica. Evidencia-se, assim, uma noção de ambiente que não se confunde com impactos na natureza, mas que privilegia as derivações e transmutações 
História da paisagem e paisagens sem história: a presença humana na Floresta Atlântica do Sudeste Brasileiro

desses lugares a partir da construção da vida em sociedade com a natureza. Ou seja, a transmutação do ecossistema em paisagem, feita pela milenar ação humana.

\section{NOTAS}

I WORSTER, D. Para fazer História Ambiental. Estudos Históricos, Rio de Janeiro, v. 4, n. 8, p. 198-215, 1981.

2 Exemplos dessas pesquisas:

INGERSON, A. E. The nature/culture dichotomy. In: CRUMLEY, C.L. (ed). Historical Ecology: cultural knowledge and changing landscapes. Santa Fe: School of American Research Press, 1993, p. 43-66; CRUMLEY, C. L. Historical ecology: a multidimensional ecological orientation. In: CRUMLEY, C.L. (ed.). Historical ecology: cultural knowledge and changing landscapes. Santa Fe: School of American Research Press, 1994, p. I-16; GARCÍA-MONTIEL, D. El legado de la actividad humana en los bosques neotropicales contemporáneos. In: GUARIGAUTA, M. R.; G.H. KATTAN. Ecología y conservación de bosques neotropicales. Cartago: Ediciones LUR, 2002, p. 97- I 12; FOSTER, D. The importance of land-use legacies to Ecology and Conservation. BioScience, Reston, vol. 53, n. I, p. 7-87, 2003; STER, D.; SWANSON, F.; ABER, J.; BURKE, I.; BROKAW, N.; TILMAN, D.; KNAPP, A. The importance of land-use legacies to ecology and conservation. BioScience, Reston, v. 53, p. 77 - 88, 2003; GIMMI, M.; BÜRGI, U. Using oral history and forest management plans to reconstruct traditional non-timber forest uses in the Swiss Rhone Valley (Valais) since the late nineteenth century. Environment and History, Isle of Harris, v. 13, p. 21 I-46, 2007.

3 RHEMTULLA, J. M.; MLADENOFF, D.J. Why history matters in landscape ecology. Landscape Ecology, Düsseldorf, v. 22, p. I-3, 2007.

4 GARCÍA-MONTIEL, D. "El legado de la actividad humana en los bosques neotropicales contemporáneos", op. cit.

5 JOLY, C. A. ; LEITÃO FILHO, H. F. ; SILVA, S. M. Patrimônio Florístico. Rio de Janeiro: Index, 199|. p. 94-125.

6 MYERS, N.; MITTERMIER, R.A.; MITTERMEIER, C.G.; FONSECA, G.A.B.; KENT, J., Biodiversity hotspots for conservation priorities. Nature, London, v. 403, p. 853-858, 2000.

7 PIUSSI, P.; FARREL, E.P. Interactions between society and forest ecosystems: challenges for the near future. Forest Ecology and Management, London, v. 132, p. 21 -28, 2000.

8 SCHEELL-YBERT, R. Mise en évidence par l'analyse anthracologique de la stabilité de la végétation sur le littoral brésilien pendant l'Holocène Supérieur. Quaternaire, Paris, v. I3, n. 3/4, p. 247-256, 2002.

9 GASPAR, M. Sambaqui: arqueologia do litoral brasileiro. Rio de Janeiro: Ed. Zahar, 2000.

${ }^{10}$ OLIVEIRA, R. R. When the shifting agriculture is gone: functionality of Atlantic Coastal Forest in abandoned farming sites. In: Boletim do Museu Paraense Emílio Goeldi. Ciências Humanas, Belém, v. 3, p. 213-226, 2008.

I' MARKS, P. L.; GARDESCU, S. Inferring forest stand history from observational field experience. In: EGAN, D.; HOWELL, E. A. (ed.). The historical ecology handbook: a restorationists's guide to 
História da paisagem e paisagens sem história: a presença humana na Floresta Atlântica do Sudeste Brasileiro

reference ecosystems. Washington, DC: Island Press, p. 177-198, 2001.

12 OLIVEIRA, R. R.; WINIWARTER, V. Toiling in Paradise: knowledge acquisition in the context of colonial agriculture in Brazil's Atlantic Forest Context of Colonial Agriculture. Environment and History, London, v. 16, p. 483-508, 2010.

${ }^{13}$ GIMMI, M.; BÜRGI, U. Using oral history and forest management plans to reconstruct traditional non-timber forest uses in the Swiss Rhone Valley (Valais) since the late nineteenth century, op. cit.

${ }^{14}$ ENGEMANN, C. Consumo de recursos florestais e produção de açúcar no período colonial o caso do Engenho do Camorim, RJ. OLIVEIRA, R. R. (Org.). As marcas do homem na floresta: história ambiental de um trecho urbano de mata atlântica. Rio de Janeiro: Ed. PUC-Rio, 2005.

${ }^{15}$ ABREU, M. A. Um quebra-cabeça (quase) resolvido: os engenhos do Rio de Janeiro nos séculos XVI e XVII. Scripta Nova, Barcelona, v. XI, p. 32, 2006.

${ }^{16}$ OLIVEIRA, R. R.; WINIWARTER, V. Toiling in Paradise: knowledge acquisition in the context of colonial agriculture in Brazil's Atlantic Forest Context of Colonial in Brazil's Atlantic Forest. Environment and History, London, v. 16, p. 483-508, 2010.

${ }^{17}$ ANTONIL, A. J. Cultura e opulência do Brasil por suas drogas e minas. Rio de Janeiro: Typ. Imp. e Const. de J. Villeneuve, 17।I.

${ }^{18}$ Velloso está se referindo às gramíneas exóticas Imperata brasiliensis Trin. (sapê) e Tristachya leiostachya Nees. (capim seta), espécies que ocorrem em terrenos degradados.

${ }^{19}$ VELLOSO, J. M. C. O Fazendeiro do Brasil. Lisboa: Oficina Régia Tipográfica, 1798. 242 p.

${ }^{20}$ FLORENTINO, M. e FRAGOSO, J. O arcaísmo como projeto: mercado atlântico, sociedade agrária e elite mercantil em uma economia colonial tardia, Rio de Janeiro, c. I 790-c. I 840. Rio de Janeiro: Civilização Brasileira, 2001.

2! ENGEMANN, C. Vida cativa: condições materiais de vida nos grandes plantéis do Sudeste Brasileiro no século XIX. In: FRAGOSO, J. et al. (org.). Nas Rotas do Império. Vitória: EDUFES, 2006, p. 423-445.

22 SCHWARTZ, S. B. Escravos, roceiros e sitiantes. Bauru: EDUSC, 2001. 305 p.

${ }^{23}$ OLIVEIRA, R. R. When the shifting agriculture is gone: functionality of Atlantic Coastal Forest in abandoned farming sites, op. cit.

${ }^{24}$ CASTRO, F; SIQUEIRA, A; BRONDIZIO, E; FERREIRA, L. Use and misuse of the concepts of tradition and property right in the conservation of natural resource in the Atlantic Rain Forest (Brazil). Ambiente e Sociedade, Campinas, v. IX, n. I, p. 23-39, 2006.

${ }^{25}$ OLMOS, F.; Correção política e biodiversidade: a crescente ameaça das populações tradicionais à Mata Atlântica. In: J. ALBUQUERQUE; J. F. CÂNDIDO; F. C. STRAUBE; A. ROOS. (Org.). Ornitologia e Conservação: da Ciência às Estratégias. Tubarão: SOB, UNISUL/CNPq, p. 279-3I2, 200 I ; OLMOS, F.; SÃO BERNARDO, C.S.; GALETTI, M. O Impacto dos Guarani sobre Unidades de Conservação em São Paulo. In: F. RICARDO. (Org.). Terras Indígenas e Unidades de Conservação da Natureza - O desafio das sobreposições territoriais. São Paulo: Instituto Socioambiental, 2004, p. 246-261.

${ }^{26}$ DIEGUES, A. C. et al. Os saberes tradicionais e a biodiversidade no Brasil. São Paulo: NUPAUB/ USP, 2000.

${ }^{27}$ WHITEHEAD, N. L. Ecological History and Historical Ecology: diachronic modeling versus 
História da paisagem e paisagens sem história: a presença humana na Floresta Atlântica do Sudeste Brasileiro

historical explanation. In: BALLÉE, W. Advances in Historical Ecology. New York: Columbia University Press, 1998. p. 30-41.

${ }^{28}$ MCGRATH, D. G. The role of biomass in shifitng cultivation. Human Ecology Heidelberg, , v. I 5 n. 2, p. $221-242,1987$.

${ }^{29} \mathrm{NAVEH}, \mathrm{Z}$. What is holistic landscape ecology? A conceptual introduction. Landscape and Urban Planning, London, v. 50, p. 7-26, 2000.

${ }^{30}$ CRUMLEY, C.L. Historical ecology: a multidimensional ecological orientation, op. cit.

${ }^{3}$ BÜRGI, M.; GIMMI, U. Three objectives of historical ecology: the case of litter collecting in Central European forests. Landscape Ecology, Düsseldorf, v. 22, p. 77-87, 2007.

32 SCHEELL-YBERT, R.; MACARIO, K.; BUARQUE, A.; ANJOS, R.M.; BEAUCLAIR, M. A. A new age to an old site: the earliest Tupiguarani settlement in Rio de Janeiro State? Anais da Academia Brasileira de Ciências, Rio de Janeiro, v. 40, n. 4, p. 763-770, 2008.

${ }^{33}$ ADAMS, C. As Florestas virgens manejadas. Boletim do Museu Paraense Emilio Goeldi. Antropologia, Belém, v. 10, n. I, p. 3-20, 1994.

${ }^{34}$ MUSSOLINI, G. Ensaios de antropologia indígena e caiçara. Rio de Janeiro: Ed. Paz e Terra, 1980.

35 OLIVEIRA, R. R. Ação antrópica e resultantes sobre a estrutura e composição da Mata Atlântica na llha Grande, RJ. Rodriguésia, Rio de Janeiro, v. 53, n. 82, p. 33-58, 2002.

${ }^{36}$ CLEMENTS, C. R.; MCCANN, J. M. NIGEL; SMITH, N. J. H. Agrobiodiversity in Amazônia and its relationship with dark earths. LEHMANN, J. et al. Amazonian Dark Earths: origins, properties and management. Dordrecht: Kluwer Academic Publishers, p. I59- I78, 2003.

${ }_{37}$ OLIVEIRA, R. R. Environmental History, Traditional Populations, and Paleo-territoires in the Brazilian Atlantic Coastal Forest. Global Environment, London, v. I, p. 176- 191, 2008.

38 Exemplos:

LÖFGREN, A. Notas sobre as plantas exóticas introduzidas no estado de São Paulo. São Paulo: ed. Revista Agrícola, 1918.

ESPÍNOLA, L. A.; H. F. J. JUNIOR. Espécies invasoras: conceitos, modelos e atributos. Interciencia, v. 32, n. 9, p. 580-585, 2007.

HEISER, C. New perspectives on the Origin and Evolution of New World Domesticated. Economic Botany, St. Louis, v. 44, n. 3, p. | | - | 16, 1990.

FERRÃO, J.E.E. A aventura das plantas e os Descobrimentos Portugueses. Lisboa: Instituto de investigação Científica nacional, Fundação Berardo, 1992.

${ }^{39}$ PERONI, N. Ecologia e genética da mandioca na agricultura itinerante do litoral sul paulista: uma análise espacial e temporal. Tese (Doutorado em Biologia Vegetal) - Instituto de Biologia, Universidade Federal de Campinas, 2004.

40 São eles: AIDAR, M. P. M.; GODOY, J. R. L.; BERGMANN, J.; JOLY, C. A. Atlantic Forest succession over calcareous soil, Parque al Turístico do Alto Ribeira - Petar, SP. Revista Brasileira e Botânica, São Paulo, v. 24, p. 455-469, 200 I; CHEUNG, C.C. Regeneração natural em áreas de Floresta Atlaântica na Reserva Natural Rio Cachoeira, Antonina, PR. Dissertação (Mestrado em Ciências Biológicas) - Universidade Federal do Paraná, 2006; DELAMONICA, P. ; LIMA, D. F; OLIVEIRA, R. R.; MANTOVANI, W. Estrutura e funcionalidade de populações de Miconia cinnamomifolia (DC.) Naud. em florestas secundárias estabelecidas sobre antigas roças caiçaras. Pesquisas. Botânica, 
História da paisagem e paisagens sem história: a presença humana na Floresta Atlântica do Sudeste Brasileiro

São Leopoldo, v. 52, p. 125- |42, 2002; TOREZAN, J.M.D. I. Estudo da sucessão secundária na Floresta Ombrófila Densa Submontana, em áreas anteriormente cultivadas pelo sistema de "coivara", em Iporanga-SP. Dissertação (Mestrado) - Setor de Ciências Agrárias, Universidade Federal do Paraná,Curitiba; LIEBSCH, D.; MARQUES, M. C. M.; GARDESCU, S. How long does the Atlantic Rain Forest take to recover after a disturbance? Changes in species composition and ecological features during secondary succession. Biological Conservation, London, v. 141, p. 1717-1725, 2008; MELO, M. M. R. F.; MANTOVANI, W. Composição florística e estrutura de trecho de Mata Atlântica de encosta na llha do Cardoso (Cananéia, SP, Brasil). Boletim do Instituto de Botânica, São Paulo, v. 9, p. 107-I 58, 1994; OLIVEIRA, R. R. Ação antrópica e resultantes sobre a estrutura e composição da Mata Atlântica na llha Grande, RJ, op. cit.; SIMINSKI, A.; MANTOVANI, M.; REIS, M. S.; FANTINI, A.C. Sucessão florestal secundária no município de São Pedro de Alcântara, litoral de Santa Catarina: estrutura e diversidade. Ciência Florestal, Santa Maria, v. I 4, p. 21-33, 2004.

${ }^{41}$ LIEBSCH, D.; MARQUES, M. C. M.; GARDESCU, S. How long does the Atlantic Rain Forest take to recover after a disturbance? Changes in species composition and ecological features during secondary succession, op. cit.

${ }^{42}$ CATALÃO, C. G.; OLIVEIRA, R. R. Estrutura da vegetação de uma floresta urbana submetida a uso de roça na década de 1970 no município do Rio de Janeiro. Eugeniana, Rio de Janeiro, v. $X X X$, p. 19-30, 2008.

${ }^{43}$ JORDAN, C. F. Nutrient cycling processes and tropical forest management. In: A. GÓMESPOMPA, T.C. WHITMOTE; HADLEY M. (ed.) Rain forest regeneration and management. London: Pub. UNESCO \& The Parthen Publ. Group, 1991. p. I59-180.

${ }^{44}$ OLIVEIRA, R. R. When the shifting agriculture is gone: functionality of Atlantic Coastal Forest in abandoned farming sites, op. cit.

45 FONSECA, D. P. R. A marca do sagrado. In: OLIVEIRA R. R. (org.). As marcas do Homem na floresta: História ambiental de um trecho urbano de Mata Atlântica. Rio de Janeiro: Ed. PUC-Rio, 2005, p. II-22.

${ }^{46}$ CARAUTA, J. P. P.; DIAZ, E. Figueiras no Brasil. Rio de Janeiro: Ed. UFRJ, 2002.

${ }^{47}$ SVORC, R. C. P. F. Figueiras centenárias, História Ambiental e estrutura da Mata Atlântica no município de Angra dos Reis, RJ. Dissertação (Mestrado em Ciências Ambientais e Florestais) Seropédica: Programa de Pós Graduação em Ciências Ambientais e Florestais, UFRRJ, 2007. 